ORIGINAL ARTICLE

\title{
Measurement of functional recovery in individuals with acute anterior cruciate ligament rupture
}

\author{
K Button, R van Deursen, P Price
}

Br J Sports Med 2005;39:866-871. doi: 10.1136/bjsm.2005.019984

Objectives: To measure functional recovery following acute anterior cruciate ligament $(A C L)$ rupture using a simple and reliable clinical movement analysis system. Clinic based methods that simultaneously quantify different aspects of movement over a range of activities and model functional recovery will help guide rehabilitation.

Methods: A longitudinal study was used to measure gait variables at initial physiotherapy attendance and then at monthly intervals using a digital camcorder and computer for quantitative analysis. Jogging and distance hopping were added during recovery. A sample of $63 \mathrm{ACL}$ deficient subjects entered the study and 48 subjects were measured at least three times. To determine the pattern of recovery, repeated measurements were analysed using a least square fit of the data.

See end of article for authors' affiliations .....................

Correspondence to: Robert van Deursen, Cardiff University, Wales, UK; vandeursenr@cardiff. ac.uk

Accepted 3 May 2005
Results: Gait variables took between 95 and 130 days post injury to reach the control mean and stabilise shortly after this. Hopping distance for the injured leg took 62 days to recover to within normal limits and 5 months post injury to reach the control mean. Jogging was already within the control limits at 30 days post injury and demonstrated little change with recovery.

Conclusions: Functional recovery of multiple variables has been modelled. In the early phase of post injury, gait velocity seems to be the most useful variable to measure improvement. Recovery of more challenging activities appears to take an average of 5 months. Therefore, patients may need to be monitored in physiotherapy until this time and advised not to return to sport until sufficient recovery is demonstrated on activities such as distance hopping.
$\mathrm{F}$ ollowing anterior cruciate ligament (ACL) rupture, altered levels of physical performance and secondary meniscal damage are commonly cited as complications with non-operative management. ${ }^{1-4}$ Despite this, not all ACL deficient (ACLD) individuals will choose to have a reconstruction. For these patients, physiotherapy rehabilitation is crucial to help them maximise their knee function and return to a level of activity that is safe..$^{5-7}$ In the United Kingdom this is complicated by long surgical waiting lists that can delay those subjects who require surgery receiving a reconstruction $^{89}$ and places a greater emphasis on rehabilitation and patient self management pre-operatively.

If an individual is receiving rehabilitation, it is important that any change in their functional ability is measured over time. This will help the clinician to make decisions about the appropriateness of treatment, to assess if the patient is achieving functional milestones, and to give advice on what activities/sport are safe for the individual to undertake. ${ }^{10}$ Functional outcome measures are recognised as having a valuable role in helping clinicians make decisions because the functional tests reflect the type of activities that patients target as acceptable outcomes. ${ }^{11-13}$

A number of studies have analysed the biomechanics of functional activities such as gait, jogging, hopping, and cutting manoeuvres in ACLD knees. They have analysed compensation strategies that include changes in joint reaction forces, moments, and powers. ${ }^{14-20}$ These studies have not collected data longitudinally, they have been restricted to individuals with chronic ACL tears, and their movement analysis systems do not fulfil the requirements of a clinical gait analysis system. ${ }^{21}$

Some validated measurement tools do exist to predict which ACLD individuals will do well with rehabilitation or delayed surgical management. ${ }^{22}{ }^{23}$ Although they are valuable screening tools, they do not provide information on the pattern of recovery over time. They have also only been designed and tested on athletes who regularly participate in activities requiring a high degree of pivoting and so may not be appropriate for those individuals who participate in leisure activities and sport at a lower level.

This means that there is a lack of information available about the course of recovery following an ACL rupture and its transition from an acute to chronic status. Important rehabilitation questions such as: how long does recovery take, at what stages is it safe to progress to more complex activities, and do functional activities ever fully recover, are left unanswered. Therefore, the aim of this study was to measure functional recovery following ACL rupture in the clinical setting.

\section{METHODS \\ Subjects}

Over the recruitment period from May 2001 to November 2003, 281 individuals attended the Acute Knee Screening Clinic (AKSS) at the University Hospital of Wales (UHW) and were diagnosed with an acute ACL rupture, which was confirmed by MRI. Sixty three of these ACLD individuals lived in the UHW physiotherapy catchment area, and on this basis were invited to enrol in the study. A convenience sample of 61 control subjects without a history of knee damage, were recruited from the same catchment area to match the ACL subjects. Participants were excluded from the study if they were under 18 or over 50 years of age, had other neurological or musculoskeletal pathology that would alter their performance, had received acute arthroscopies, and had

Abbreviations: $\mathrm{ACL}$, anterior cruciate ligament; $\mathrm{ACLD}, \mathrm{ACL}$ deficient; AKSS, Acute Knee Screening Clinic; UHW, University Hospital of Wales 


\begin{tabular}{|c|c|c|c|}
\hline Characteristic & Mean (SD) & $95 \% \mathrm{Cl}$ & p value \\
\hline \multicolumn{4}{|l|}{ Height $(\mathrm{cm})$} \\
\hline $\mathrm{ACL}$ & $171.7(9.4)$ & 4.34 to 3.14 & 0.912 \\
\hline Control & $171.9(9.4)$ & & \\
\hline \multicolumn{4}{|l|}{ Age (years) } \\
\hline $\mathrm{ACL}$ & $27.5(7.7)$ & -2.83 to 1.88 & 0.961 \\
\hline Control & $27.6(5.6)$ & & \\
\hline \multicolumn{4}{|l|}{ Weight $(\mathrm{kg})$} \\
\hline $\mathrm{ACL}$ & 72.9 (13.0) & -4.81 to 6.45 & 0.899 \\
\hline Control & 72.5 (13.8) & & \\
\hline \multicolumn{4}{|l|}{ Gender } \\
\hline $\mathrm{ACL}$ & Male/female & & 0.775 \\
\hline Control & Male/female & & \\
\hline
\end{tabular}

The $95 \%$ confidence intervals of the difference between groups and the significance level calculated through an independent $t$ test are shown $(\alpha$ level $=0.05$ ).

locked knees or combined ACL and posterior cruciate ligament injuries. However, ACL injuries combined with MCL tears or asymptomatic meniscal tears were included. This study was approved by the South Wales Local Research and Ethics Committee. All patients followed a standardised rehabilitation program that incorporated strengthening and neuromuscular control activities. This was staged according to symptoms and time post injury. ${ }^{24} 25$

\section{Repeated measurements over time}

On initial attendance all ACL patients were given a study information sheet. Data collection started on their second visit after they had provided written informed consent. Forty eight participants underwent a minimum of three movement analysis recording sessions and were therefore included in this sample. Recordings for gait analysis were made at approximately monthly intervals. As they progressed through rehabilitation, jogging and distance hopping were also recorded if subjects had minimal resolving effusion, full range of knee motion, and no episodes of full giving way. ${ }^{23-27}$

\section{Clinical movement analysis}

All data collection took place in the gym of the physiotherapy department at UHW. The walkway used was $15 \mathrm{~m}$ long. Two sticks with markers at either end were placed midway along the walkway, parallel to each other and $1 \mathrm{~m}$ apart for calibration and data processing. A digital camcorder (SONY Digital Handycam DCR-PC110E) was placed $6 \mathrm{~m}$ away from the walkway and $1 \mathrm{~m}$ above the ground on a tripod perpendicular to the direction of movement. Instructions given to the subjects for gait and jogging were to move at

Table 2 Summary of patient characteristics for the recruited ACLD sample (1) and all ACLD subjects who attended the AKSS (2)

\begin{tabular}{lllll}
\hline Characteristic & Group & Mean (SD) & Range & Ratio, M/F \\
\hline Age, years & 1 & $27.5(7.7)$ & $18-53$ & \\
Gender & 2 & $29.6(9.2)$ & $15-58$ & $38 / 25$ \\
& 1 & & & $170 / 44$ \\
\hline \multicolumn{4}{l}{ M/F, male/female. } \\
\end{tabular}

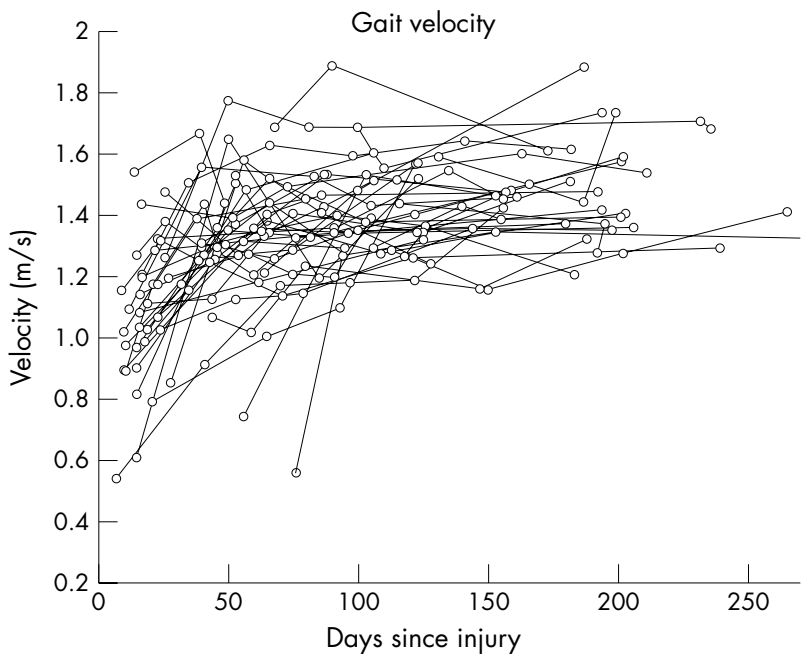

Figure 1 Recovery over time of gait velocity for each individual ACLD patient. Each data collection visit is represented by an empty circle with a line joining individual visits.

their comfortable speed along the length of the walkway. Two trials were collected, one in either direction.

For maximal hopping distance, subjects were instructed to start on their testing limb, hop as far as they could, and land on their testing limb, maintaining their balance until instructed to move away. Distance was measured on both the injured and non-injured limbs of patients.

\section{Data analysis and processing}

All data were processed using a SONY VAIO FX105 laptop with DVGait and MATLAB 12 software. Individual frames corresponding to events of interest were saved from the video and stored as JPEG files. For gait and jogging these were three heel strikes of the subject walking in either direction and for hopping frames corresponding to pre take off and landing. Temporal information of these events was obtained from frames from the display in DVGait (resolution: 25 frames per second). For stage two of the processing, a program was purpose written in MATLAB. The two $1 \mathrm{~m}$ sticks were used to calibrate the area between them and create a grid so that the placement of the foot (location of the heel in contact with the floor at heel strike) relative to the calibration sticks could be measured. This spatial information was obtained automatically by the computer after the operator had indicated the heel location by means of a cross hair displayed on the computer screen. Once this temporal and spatial information was processed, the following variables could then be analysed by the computer: gait and jogging velocity, cadence, step length, gait step length symmetry, and maximal hopping distance.

The reliability of this system for calculating gait velocities has been found to be high, with an inter-tester reliability of ICC $=0.99$ and reliability between assessors and an optoelectric timer of ICC $=0.98 .^{28}$

\section{Statistical analysis}

Independent $t$ tests and $\chi^{2}$ tests were used to compare the ACL and control groups. The same approach was used to check that the ACL subject sample participating in the study was representative of the larger population of all ACL subjects attending the AKSS. As indicated earlier, ACLD subjects needed to have a minimum of three monthly recordings of their gait to be entered for further analysis. Data from the 


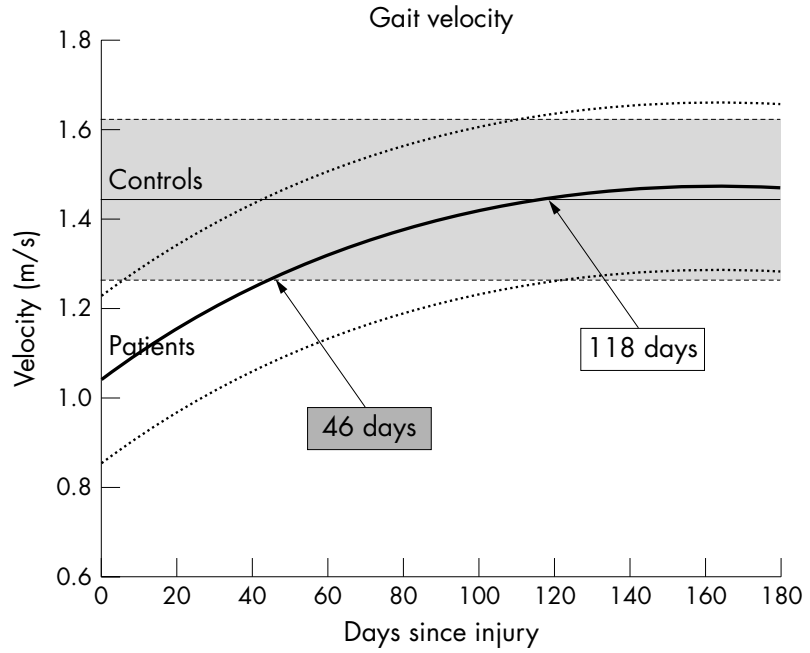

Figure 2 Recovery over time of gait velocity. The ACLD group is indicated by the solid curved line with 1 SD indicated by the dotted lines. The reference values derived from the control group (average \pm 1 SD) are indicated by the horizontal shaded band with straight grey lines.

control group were used to calculate means and standard deviations (SD) of the different parameters. Members of the ACL group were classified as having recovered to within a normal range when their values were within \pm 1 SD of the control mean. ${ }^{29}$ Changes over time indicative of functional recovery in the ACL group were modelled using a least square fit of the data. Because functional recovery was non-linear, a third order polynomial curve fit was used with "days since injury" as the independent variable to a maximum of 180 days since injury. In addition, I SD around this fit line was calculated.

All data from the control and ACL groups were plotted against time (in days) to permit a descriptive exploration of recovery. Two events were noted: the time when the ACL group returned within the range of values found in the control group (average \pm 1 SD) and the time when

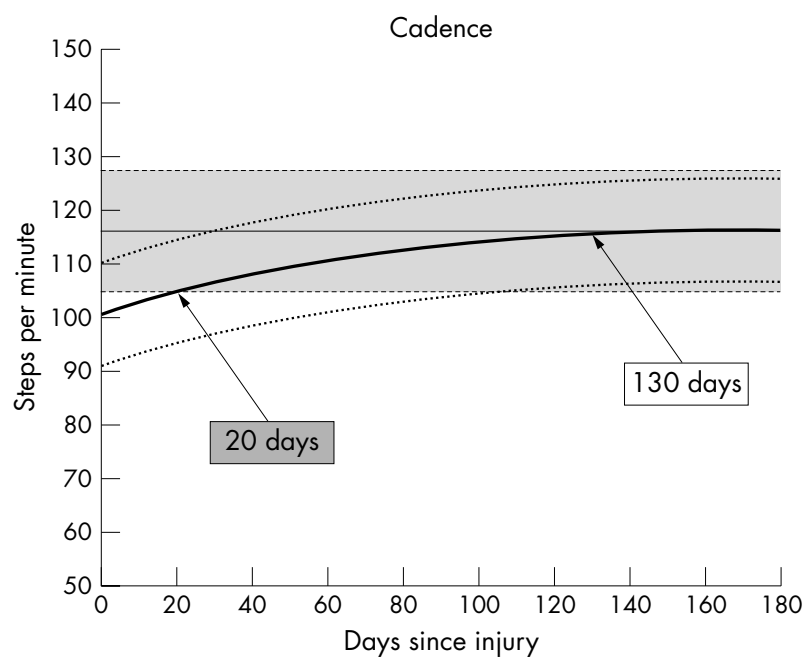

Figure 3 Recovery over time of cadence. The ACLD group is indicated by the solid curved line with 1 SD indicated by the dotted lines. The reference values derived from the control group (average \pm 1 SD) are indicated by the horizontal shaded band with straight grey lines.

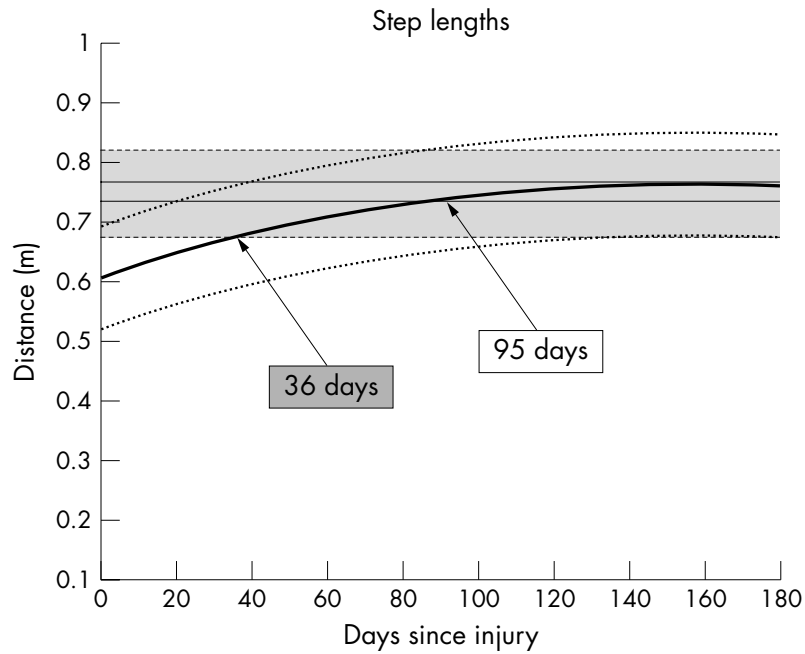

Figure 4 Recovery over time of step lengths. The ACLD group is indicated by the solid curved line with 1 SD indicated by the dotted lines. The reference values derived from the control group (average \pm 1 SD) are indicated by the horizontal shaded band with straight grey lines.

the ACL group returned to the average value of the control group.

\section{RESULTS}

The control and ACLD groups were matched for age, height, weight, gender, and activity levels (table 1).

Patient characteristics of the ACL sample recruited in this investigation compared to all ACLD subjects who attended the AKSS are summarised in table 2.

\section{Gait}

The raw data for recovery of gait velocity for each individual ACLD subject over time have been plotted in fig 1 for the purpose of illustration. The average recovery for all gait variables have been plotted in figs $2-5$. The first gait variable to return to within the control reference value was cadence,

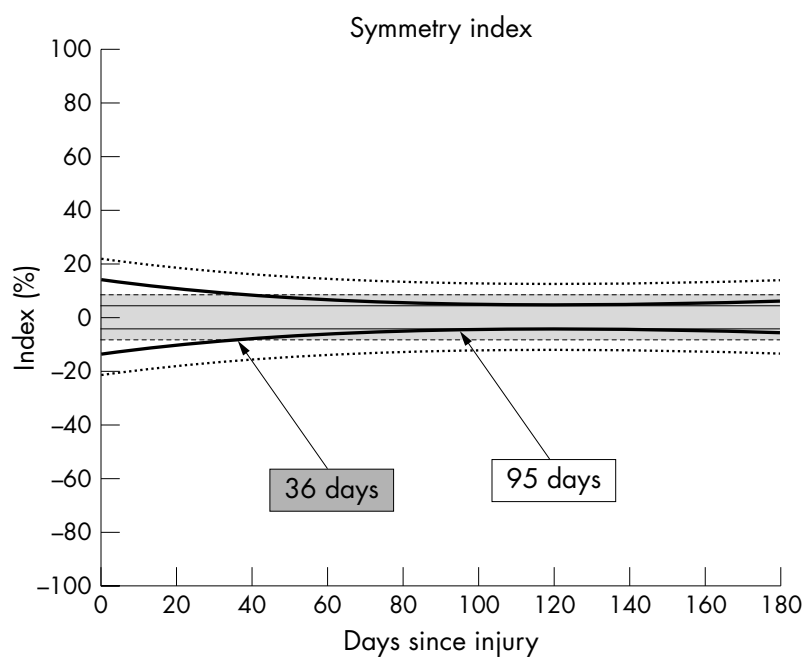

Figure 5 Recovery over time of step length symmetry. The ACLD group is indicated by the solid curved line with 1 SD indicated by the dotted lines. The reference values derived from the control group (average \pm 1 SD) are indicated by the horizontal shaded band with straight grey lines. 


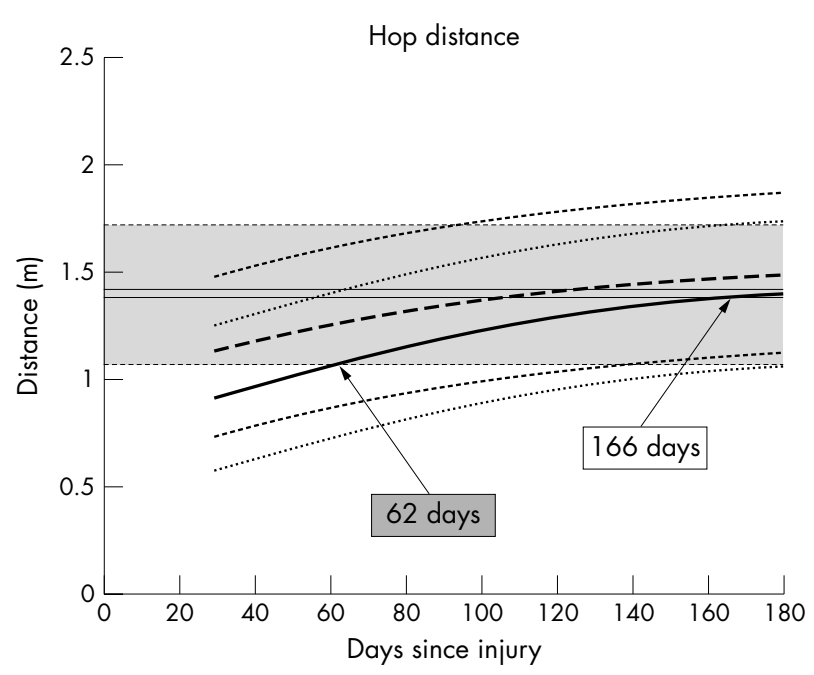

Figure 6 Recovery over time of maximal hopping distance. The ACLD group is indicated by the solid curved line with 1 SD indicated by the dotted lines. The reference values derived from the control group (average $\pm 1 \mathrm{SD}$ ) are indicated by the horizontal shaded band with straight grey lines.

followed by step length, step symmetry, and gait velocity. Once all the gait variables stabilised at the control mean, both groups walked at a self selected velocity of $1.43 \mathrm{~m} / \mathrm{s}$, with a cadence of 116 steps per minute, step length of $0.73 \mathrm{~m}$, and $5 \%$ asymmetry between limbs.

\section{Hopping distance}

Recovery of hopping distance from the time of injury for the injured and non-injured limbs is plotted in fig 6. At 166 days post injury, the average hopping distance of the injured limb in the ACLD subjects was $1.3 \mathrm{~m}$ and starting to stabilise close to the control average of $1.4 \mathrm{~m}$. Initially the hopping distance of the non-injured ACLD limb was shorter than that of the control subjects but by 108 days post injury had reached the control mean. The difference in hopping distance between the injured and non-injured limb decreased with time from injury.

\section{Jogging}

Some ACLD subjects start jogging as early as 30 days post injury and jogging velocity, step length, and cadence were all within \pm 1 SD of the control subjects. Over time there is very little change in these variables. Average jogging velocity for controls was $3 \mathrm{~m} / \mathrm{s}$ and for ACLD subjects $2.9 \mathrm{~m} / \mathrm{s}$. Average step length for both groups was $1.1 \mathrm{~m}$.

\section{DISCUSSION}

In this study, a number of functional activities were measured repeatedly during recovery in a group of acutely injured ACLD patients. The results for the gait variables and jogging velocity analysed in this study, are comparable to those found in the literature, ${ }^{16} 18203031$ but the average hopping distances are slightly shorter than those described elsewhere. ${ }^{132}$ This may be due to the subjects in this study participating in all levels and types of sport, not just high level pivoting and cutting activities. The hopping distance of the non-injured limb did recover to the control mean as was expected, ${ }^{33}$ but the results of other studies have indicated that this may not always be the case. ${ }^{32}$ The initial reduction in hopping distance in the non-injured limb could have been due to over protection in the acute stage post injury. ${ }^{31}$ This would indicate that it is not appropriate to use contralateral performance as a reference to evaluate if hopping distance has recovered in the injured limb.

Initially following injury, gait is the only activity that patients can perform, due to an effusion, restricted range of motion, pain, and sensation of knee instability. This study indicated that gait variables took far longer to recover than was anticipated, between 20 and 46 days to be within the control reference values and between 95 and 130 days to reach the control mean and even longer to plateau. Initial quick recovery of cadence to within control limits meant that patients were compensating by walking with more but shorter steps. This strategy may have been adopted during the acute phase to ensure knee stability in the presence of swelling and restricted knee range of motion. Because gait is a basic movement required for many activities of daily living, its lengthy recovery makes it ideally suited to monitoring functional recovery in the early stages post injury, before individuals can perform more challenging activities. The only other study to monitor functional recovery of ACLD subjects over time found using visual analysis that it took between 2.8 and 4 weeks to achieve independent, non-antalgic gait. ${ }^{34}$ The speed of this recovery is possibly due to using a different less sensitive method of gait analysis.

Distance hopping had a slower recovery than gait and jogging and was stabilising at 5 months post injury. This would indicate that it is a more difficult activity for ACLD subjects and should be introduced later in rehabilitation. ${ }^{24}$ Unlike gait and jogging, it challenges a different aspect of knee stability. In order to successfully land from a hop, individuals need to be able to control large vertical and, in particular, knee joint shear forces, coupled with large extensor moments and rapid deceleration. ${ }^{1535} 36$ Although hopping distance is an easy measure, it would not be recommended that a decision about return to sport is made from this variable alone. Several other studies have demonstrated that a battery of outcome measures need to be used to predict if an individual can return to contact sport. $^{1322} 23$

Jogging velocity, cadence, and step lengths demonstrated very little change during recovery. Cadence and step length did recover to the control mean, but the jogging velocity for ACLD subjects consistently performed just below this. There is some disagreement in the literature as to whether jogging velocity and cadence do fully recover following ACL rupture. ${ }^{14} 16$ Overall jogging did not provide any information additional to gait on the recovery of function. Jogging is still an important functional activity because it is essential for the safe return to many sports, but its value as a functional outcome measure was not found to be evident in this study. Instead, it might be advisable to include an analysis of run and rapid direction change in the clinical movement analysis, because it is a lack of rotational stability that often causes individuals' knees to give way on return to full activity. ${ }^{137}$

Analysis of functional activities in the clinical setting provides clinicians with a greater understanding of what these activities involve. This will allow them to provide more appropriate advice to patients about recovery times and activities they can safely undertake. It will also enable clinicians to set more realistic rehabilitation goals and together this may improve patient compliance, ${ }^{38}$ reducing the number of episodes of knees giving way and being further damaged. ${ }^{1} 39$

Based on our results, it is anticipated that full functional recovery on average could take up to 5 months or longer. It may be even slower if an individual has not attended a full course of rehabilitation or was delayed receiving treatment. There are no clear guidelines in the literature suggesting how 


\section{What is already known on this topic}

Functional recovery following acute $\mathrm{ACL}$ rupture has not previously been measured longitudinally using clinically relevant functional variables. Important rehabilitation questions about length of recovery and time to return to sport remain unanswered.

\section{What this study adds}

Functional recovery has been measured using simple clinical variables and has been found to take up to 5 months. Clinicians can use this information to give better advice to patients about individual recovery and provide more structure for rehabilitation on the basis of functional activities.

long it could take ACLD individuals to return to sport, but anything between 4 months post injury to never returning have been reported. ${ }^{50}$ For the clinician this indicates that individuals could be attending physiotherapy over a prolonged period of time, requiring significant amounts of treatment.

Compared to all patients attending the AKSS, this study sample of ACL subjects contained more female subjects and a greater proportion of individuals participating in sports requiring a high degree of pivoting. This is probably due to the presence of a sports college within the catchment area. This makes it all the more surprising that, despite the higher proportion of high level athletes in this sample, recovery of the functional variables still took a considerable time.

Measuring functional recovery of ACLD patients from initial injury over time in the clinical setting is unique. Analysis of gait provided information on movement compensations and recovery in the early stages following injury, when it would be unsafe to perform sports specific functional activities such as hopping. The jogging variables analysed in this study provided little information on functional recovery. Clinicians can compare this model of functional recovery with individual patient performance to see if patient function is following a typical path of recovery. Overall functional recovery has been found to take a considerable amount of time: 3-4 months for gait and 5 for hopping. This means that patients may need to be treated in physiotherapy until this time and advised not to return to sport until a full recovery is demonstrated on activities such as distance hopping.

\section{ACKNOWLEDGEMENTS}

We would like to thank the Physiotherapy Department, University Hospital of Wales, and the Research and Development Department, University Hospital of Wales, Cardiff.

\section{Authors' affiliations \\ K Button, R van Deursen, Department of Physiotherapy, Cardiff \\ University, Cardiff, UK \\ P Price, Wound Healing Research Unit, Cardiff University, Cardiff, UK \\ Competing interests: none declared}

\section{REFERENCES}

1 Scavenius M, Bak K, Hansen S, et al. Isolated total ruptures of the anterior cruciate ligament - a clinical study with long-term follow-up of 7 years. Scand J Med Sci Sports 1999;9:114-19.
2 McAllister DR, Tsai AM, Dragoo JL, et al. Knee function after anterior cruciate ligament injury in elite collegiate athletes. Am J Sports Med 2003;31:560-3.

3 Daniel DM, Stone ML, Dobson BE, et al. Fate of the ACL-injured patient. A prospective outcome study. Am J Sports Med 1994;22:632-44.

4 Grontvedt T, Heir S, Rossvoll I, et al. Five-year outcome of 13 patients with an initially undiagnosed anterior cruciate ligament rupture. Scand J Med Sci Sports 1999:9:62-4.

5 Fitzgerald GK, Axe MJ, Snyder-Mackler L. The efficacy of perturbation training in nonoperative anterior cruciate ligament rehabilitation programs for physically active individuals. Phys Ther 2000;80:128-40.

6 Marx RG, Jones EC, Angel M, et al. Beliefs and attitudes of members of the American Academy of Orthopaedic Surgeons regarding the treatment of anterior cruciate ligament injury. Arthroscopy 2003;19:762-70.

7 Mirza F, Mai DD, Kirkley A, et al. Management of injuries to the anterior cruciate ligament: results of a survey of orthopaedic surgeons in Canada. Clin J Sport Med 2000; 10:85-8.

8 de Roeck NJ, Lang-Stevenson A. Meniscal tears sustained awaiting anterior cruciate ligament reconstruction. Injury 2003;34:343-5.

9 Karlsson J, Kartus J, Magnusson L, et al. Subacute versus delayed reconstruction of the anterior cruciate ligament in the competitive athlete. Knee Surg Sports Traumatol Arthrosc 1999;7:146-51

10 Flanagan $T$, Coburn $P$, Harcourt $P$, et al. Justifying the on-going physiotherapy management of long-term patients. Man Ther 2003;8:254-6.

11 Barber SD, Noyes FR, Mangine RE, et al. Quantitative assessment of functional limitations in normal and anterior cruciate ligament-deficient knees. Clin Orthop 1990;255:204-14.

12 Fitzgerald GK, Lephart SM, Hwang JH, et al. Hop tests as predictors of dynamic knee stability. J Orthop Sports Phys Ther 2001;31:588-97.

13 Itoh $\mathbf{H}$, Kurosaka M, Yoshiya S, et al. Evaluation of functional deficits determined by four different hop tests in patients with anterior cruciate ligament deficiency. Knee Surg Sports Traumatol Arthrosc 1998;6:241-5

14 Rudolph KS, Eastlack ME, Axe MJ, et al. 1998 Basmajian Student Award Paper: Movement patterns after anterior cruciate ligament injury: a comparison of patients who compensate well for the injury and those who require operative stabilization. J Electromyogr Kinesiol 1998;8:349-62.

15 Rudolph KS, Axe MJ, Snyder-Mackler L. Dynamic stability after ACL injury: who can hop? Knee Surg Sports Traumatol Arthrosc 2000;8:262-9

16 Rudolph KS, Axe MJ, Buchanan TS, et al. Dynamic stability in the anterior cruciate ligament deficient knee. Knee Surg Sports Traumatol Arthrosc 2001;9:62-71.

17 Chmielewski TL, Rudolph KS, Fitzgerald GK, et al. Biomechanical evidence supporting a differential response to acute $\mathrm{ACL}$ injury. Clin Biomech (Bristol, Avon) 2001;16:586-91.

18 Alkjaer T, Simonsen EB, Jorgensen U, et al. Evaluation of the walking pattern in two types of patients with anterior cruciate ligament deficiency: copers and non-copers. Eur J Appl Physiol 2003;89:301-8.

19 Ferber R, Osternig LR, Woollacott MH, et al. Gait perturbation response in chronic anterior cruciate ligament deficiency and repair. Clin Biomech (Bristol, Avon) 2003;18:132-41

20 Roberts CS, Rash GS, Honaker JT, et al. A deficient anterior cruciate ligament does not lead to quadriceps avoidance gait. Gait Posture 1999:10:189-99.

21 Coutts F. Gait analysis in the therapeutic environment. Man Ther $1999 ; 4: 2-10$

22 Fitzgerald GK, Axe MJ, Snyder-Mackler L. A decision-making scheme for returning patients to high-level activity with nonoperative treatment after anterior cruciate ligament rupture. Knee Surg Sports Traumatol Arthrosc 2000;8:76-82.

23 Eastlack ME, Axe MJ, Snyder-Mackler L. Laxity, instability, and functional outcome after ACL injury: copers versus noncopers. Med Sci Sports Exerc 1999;31:210-15.

24 Fitzgerald GK, Axe MJ, Snyder-Mackler L. Proposed practice guidelines for nonoperative anterior cruciate ligament rehabilitation of physically active individuals. J Orthop Sports Phys Ther 2000;30:194-203.

25 Manal TJ, Snyder-Mackler L. Practice guidelines for ACL rehabilitation: criteria based rehabilitation progression. Oper Techn Orthop 1996;6:190-6.

26 Zatterstrom R, Friden $T$, Lindstrand $A$, et al. Rehabilitation following acute anterior cruciate ligament injuries - a 12-month follow-up of a randomized clinical trial. Scand J Med Sci Sports 2000;10:156-63.

27 Irrgang JJ, Fitzgerald GK. Rehabilitation of the multiple-ligament-injured knee. Clin Sports Med 2000;19:545-71.

28 van Deursen RWM, Button K, Lawthom C. Measurement of spatial and temporal gait parameters using a digital camcorder. Gait Posture 2001;14:128.

29 Kendall PC, Marrs-Garcia A, Nath SR, et al. Normative comparisons for the evaluation of clinical significance. J Consult Clin Psychol 1999;67:285-99.

30 Besier TF, Lloyd DG, Cochrane JL, et al. External loading of the knee joint during running and cutting maneuvers. Med Sci Sports Exerc 2001;33:1168-75.

31 Bush-Joseph CA, Hurwitz DE, Patel RR, et al. Dynamic function after anterior cruciate ligament reconstruction with autologous patellar tendon. Am J Sports Med 2001;29:36-41.

32 Gauffin H, Pettersson G, Tropp H. Kinematic analysis of one leg long hopping in patients with an old rupture of the anterior cruciate ligament. Clin Biomech (Bristol, Avon) 1990;5:41-6. 
33 Muneta T, Ogiuchi T, Imai S, et al. Measurements of joint moment and knee flexion angle of patients with anterior cruciate ligament deficiency during level walking and on one leg hop. Biomed Mater Eng 1998;8:207-18.

34 Johnson DL, Bealle DP, Brand JC Jr, et al. The effect of a geographic lateral bone bruise on knee inflammation after acute anterior cruciate ligament rupture. Am J Sports Med 2000;28:152-5.

35 Simpson KJ, Pettit M. Jump distance of dance landings influencing internal joint forces: II. Shear forces. Med Sci Sports Exerc 1997;29:928-36

36 Colby S, Francisco A, Yu B, et al. Electromyographic and kinematic analysis of cutting maneuvers. Implications for anterior cruciate ligament injury. Am J Sports Med 2000;28:234-40.

37 Houck J, Yack HJ. Giving way event during a combined stepping and crossover cutting task in an individual with anterior cruciate ligament deficiency. J Orthop Sports Phys Ther 2001;31:481-9.

38 Scherzer CB, Brewer BW, Cornelius AG, et al. Psychological skills and adherence to rehabilitation after reconstruction of the ACL.J Sport Rehabil $2001 ; 10: 165-72$

39 Allen CR, Wong EK, Livesay GA, et al. Importance of the medial meniscus in the anterior cruciate ligament-deficient knee. J Orthop Res 2000;18:109-15

40 Myklebust G, Holm I, Maehlum S, et al. Clinical, functional, and radiologic outcome in team handball players 6 to 11 years after anterior cruciate ligament injury: a follow-up study. Am J Sports Med 2003;31:981-9.

\section{COMMENTARY}

This article addresses a clinically relevant topic, that is, functional recovery after anterior cruciate ligament injury. The approach of monitoring the functional restoration of the individual patient or athlete definitely appears worthwhile. It provides the clinician and/or therapist with information that will be useful for recommendations regarding the athlete's return to sporting activities. It is especially helpful that the authors monitored different activities that provided varying levels of challenge to the knee joint. Therefore, the information presented here should help when devising specific training regimes for individual patients in order to help them regain full functional performance.

Kinesiology Laboratory, University of Muenster, Muenster, Germany; diro@uni-muenster.de

\section{ELECTRONIC PAGES}

\section{Online short and case reports}

7 he following electronic only articles are published in conjunction with this issue of BJSM

Sit to stand transfer: performance in rising power, transfer time and sway by age and sex in senior athletes

J B Feland, R Hager, R M Merrill

Objective: To observe the differences in performance variables of the sit to stand transfer (as measured on the NeuroCom Balance Master) in a population of senior athletes.

Method: A convenience sample of 173 subjects aged 50 years and older. Data were obtained from voluntary participation in a health fair offered at the annual Huntsman World Senior Games in St George, Utah, USA. All sit to stand tests were performed on the NeuroCom Balance Master. The measured parameters were weight transfer time (WTT), rising power (force exerted to rise), and centre of gravity sway (COG sway) during the rising phase.

Results: A significant difference was found between stratified age groups (50-64 and 65+ years) on rising power. There was also a sex difference in rising power. No significant differences were found in weight transfer time or COG sway.
Conclusion: While rising power decreases with increasing age in senior athletes, WTT and COG sway remain similar regardless of age or sex. The maintenance of these other two variables (WTT and COG sway) may be attributable to physical activity and/or participation in sport.

(Br J Sports Med 2005;39:e39) http://bjsm.bmjjournals.com/ cgi/content/full/39/9/e39

\section{Thrower's fracture of the humerus with radial nerve palsy: an unfamiliar softball injury}

P Curtin, C Taylor, J Rice

A fracture of the normal humerus in a healthy young adult most commonly results from significant direct trauma. Throwing sports have become increasingly popular outside of North America and bring with them a novel injury mechanism for clinicians. A 21 year old woman sustained a "thrower's fracture" of the distal humerus and radial nerve palsy while throwing a softball. She was treated by internal fixation. Her fracture united, and radial nerve neurapraxia resolved after 8 weeks. Clinicians should be aware of this entity so that prodromal symptoms can be recognised early and thrower's fractures are not investigated unnecessarily.

(Br J Sports Med 2005;39:e40) http://bjsm.bmjjournals.com/ cgi/content/full/39/9/e40 